\title{
Integrated Automatic Control of Water, Fertilizer and Pesticide Based on Weather Change in Intelligent Agriculture
}

\author{
Xiping Wen \\ College of Communication Engineering \\ Chengdu University of Information Technology \\ Chengdu, China
}

\author{
Bin Wen \\ College of Communication Engineering \\ Chengdu University of Information Technology \\ Chengdu, China
}

\begin{abstract}
In the process of planting crops, it is greatly affected by the growing environment. The effects of weather, watering, fertilization, and pesticide s are important for the growth of crops and the final harvest. In order to cope with the bad weather, agricultural greenhouses have emerged. In order to make watering, fertilization and pesticide s more convenient and effective, water and fertilizer integrated control equipment has emerged. But so far, there have been no equipment facilities that can combine several, so that it is impossible to fundamentally solve the impact of weather and water and fertilizer on crops. In order to further promote the development of modern agriculture and fundamentally solve the problem of crop growth, this paper puts forward the automatic control equipment of dynamic water, fertilizer and pesticide, which adjusts the dynamic water, fertilizer and pesticide according to the different dynamic changes of weather, soil properties and crop varieties.
\end{abstract}

Keywords: Intelligent agriculture, integration of water, fertilizer and pesticide, weather, automation and dynamic change

\section{INTRODUCTION}

The integrated technology of water, fertilizer and pesticide is a new agricultural technology that integrates irrigation, fertilization and pesticides. It has "three festivals" (water saving, fertilizer saving, pesticide saving), "three provinces" (work saving, labor saving, worry saving) and the good effect of "three increases" (increasing production, increasing income, and increasing efficiency) is the "No. 1 Technology" for developing modern agriculture and accelerating the transformation of agricultural development methods ${ }^{[1]}$.

At present, the water, fertilizer and pesticide integrated control unit on the market adopts three fixed working modes: fixed parameter setting, starting timing and fixed number of times. The method is adopted by storing the water consumption, the amount of fertilizer and the dosage of different root lengths of different crops during the growth period in the storage module. The digitizer and the timer are connected to the controller to realize the timing and the number of times of starting the pump and the fertilizer pump. Once the number of times and timing are configured, it cannot be adjusted in real time according to the weather changes. Even if there is obvious precipitation process tomorrow, the whole process must be completed according to the set method ${ }^{[2]}$. Due to the different planting objects and different planting areas, the three-level mode has a large amount of control unit configuration information and it is inconvenient to modify the control parameters on site. Moreover, it is also necessary to face the problem of reconfiguring parameters when the user replaces the product. In short, this mode is a mode in which all the workflows set by the operator are automatically completed after the operator starts the control flow and the control scheme. Regardless of the changing weather conditions, regardless of the actual situation of crop growth, the mode of working according to the pre-set process, after years of practice, is increasingly unsuitable for the needs of modern agricultural development.

To this end, we design a control method that dynamically adjusts water spray, fertilization, and pesticide spray according to different actual conditions such as planting objects, soil properties, and weather changes ${ }^{[3]}$. Fully invoke the role of meteorological big data in all key aspects of crop growth, and dynamically influence or change the operational process of water and fertilizer integration.

\section{PROPOSAL OF A NEW METHOD}

This method of dynamically adjusting the integration process of water, fertilizer and pesticide according to the actual situation of planting objects, soil properties, weather changes, etc. is realized in three stages, without additional memory, timers and counters. Only one STM32 core micro-control chip is needed to realize the design difficulty of the controller, and the amount of data scheduled by the controller is also greatly reduced, the use is simple, convenient, and the cost is greatly reduced. The first stage is called the water diversion stage (or water diversion time). Depending on the crop object, the crop root system is different from the fertilizer absorption method, and the length of time is determined. At this stage, only water is not fed, making a certain water content around the root of the crop, so that the fertility quickly penetrates into the place where the root of the crop needs the most fertility. The length of time is determined by water pressure, pipe network size, crop objects, and the like ${ }^{[4]}$. The second stage, called the topdressing stage (or topdressing time), determines the amount of fertilizer used depending on the crop growth period and the nature of the soil. Since the input pipe network is fixed, the water pressure is fixed, the fertility conveying rate is constant, and the time of topdressing is calculated according to the amount of fertilizer. The third stage is the hydration stage (or replenishment time). The purpose is to transfer all the fertilizer on the pipeline to the field and fertilize it to the ground as needed. The length of time is still determined according to the needs of the crop.

In the actual production process of agriculture, the operation process of water, fertilizer and pesticide integration should be dynamic, and the time adjustment of the three stages is not only based on the three different situations above. More importantly, it is necessary to dynamically change the three times according to the weather conditions, as well as the workflow of the water, fertilizer and pesticide controller. The method is to determine the total amount of water theoretically required for each growth 
stage, and calculate the water diversion time, top dressing time, and water replenishment time from the ratio of water to fertilizer and water to pesticide ${ }^{[5]}$. The process of introducing meteorological elements into the integrated water, fertilizer and pesticide process is based on the temperature and humidity of the air in the first three days and the water content of the soil and the forecast of key climatic factors in the region over the next three days to change the work flow and farming arrangements of the water, fertilizer and pesticide.

To this end, the water, fertilizer and pesticide integrated control device not only needs to achieve three stages of control functions, but also complete the collection of key climatic factors (such as air temperature, humidity, soil moisture, etc.). At the same time, it can remotely receive relevant parameters and weather forecast information of the cloud data center, and integrate it into the whole control process of water and fertilizer integration to accurately realize modern fertilization and fight drugs. Fully achieve the purpose of "three festivals", "three provinces" and "three increases" to minimize the impact of chemical raw materials on the environment ${ }^{[6]}$.

\section{THE REALIZATION PRINCIPLE OF THE INTEGRATED CONTROL SCHEME OF DYNAMIC WATER, FERTILIZER AND PESTICIDE}

\subsection{Meteorological information acquisition}

(1) The automatic control device collects relevant climatic elements every 10 minutes and stores them in the local memory. At the same time, the NBIO IoT communication module obtains temperature, precipitation and other related forecast information from the weather network.

(2) Use the SQLIT database in the device memory to store the latest 10 days of climate data collected by itself and weather forecast information within 3 days.

\subsection{Meteorological Information Processing}

\subsubsection{Data preprocessing}

Meteorological information is processed in units of time in the integrated control of water, fertilizer and pesticide. First, data quality control is performed to extract or correct useful meteorological information data; the average value of each climatic element, the maximum value and the minimum value of each day are calculated again, and stored in the data table.

\subsubsection{Advanced processing of core meteorological elements} In this algorithm, deep meteorological processing of temperature, water, light and other core meteorological elements is required. For example, data such as accumulated temperature, daily difference, illumination duration, and precipitation frequency satisfying certain conditions are calculated and stored in the data table. The table is stored in the latest 10 days of data.

\subsection{Design of Integrated Control Algorithm for Water, Fertilizer and Pesticide}

In the design of the integrated control algorithm of water, fertilizer and pesticide, the weather condition should be prejudgized, according to the different period of crop growth, the changing weather conditions, and the weather forecasting situation of the water and fertilizer integration process. Through the new control algorithm to change the current water, fertilizer and pesticide integration process can not be changed according to the actual situation, only according to the set, timing, quantitative, fixed process three fixed operational procedures $^{[7]}$. Through the integration process of water, fertilizer and pesticide integration into the changing weather process, the refined water and fertilizer integration process is completed, and the pesticide spraying process is more refined and intelligent to reduce pesticide residues and dosage.

\subsubsection{Conditional calculation of core meteorological indicators}

Activity accumulated temperature: $A a=\sum_{i=1}^{n} T_{i}\left(T_{i}>B\right.$;

When $\left.T_{i} \leq B, T_{i}=0\right), T_{i}$ is temperature data after quality control; $B$ is a certain minimum temperature required for planting objects; $N$ is 30 , and the equipment stores real-time data for 30 days.

Effective accumulated temperature: $A e=\sum_{i=1}^{n}\left(T_{i}-B\right)$

$\left(T_{i}>B\right.$; When $\left.T_{i} \leq B, T_{i}=0\right)$.

Frequency counting: $N a=\coprod_{i=1}^{n} X_{i}\left(X_{i}>B\right), \quad N a$ plus 1 , when $X_{i} \leq B, N a$ is unchanged. $X_{i}$ is a meteorological element (such as temperature, temperature, etc.).

Diurnal range: $B a=T_{i}-T_{j}$; The difference between the average daily temperature of $T_{i}$ from 08 am to $20 \mathrm{pm}$ and the average daily temperature from $20 \mathrm{pm}$ to $08 \mathrm{am}$ ).

Sunshine duration: $S n=X_{i}-X_{j} ; X_{i}$ is the daily sunshine time data from the sensor at 8:00 am; $X_{j}$ is the number of hours of sunshine read from the sensor at $20 \mathrm{pm}$ every day.

3.3.2 Farming activity weather grade discrimination rules Watering, fertilizing, and spraying pesticide are all agricultural activities in agricultural production. It is necessary to first determine whether this farming activity is appropriate. The rules for determining meteorological conditions are as follows:

If all the conditions for a certain agricultural activity are appropriate, the meteorological level of the agricultural activity is appropriate;

If the arbitrary discriminant condition of a certain agricultural activity is unsuitable, the meteorological level of the agricultural activity is not suitable;

In other cases, the meteorological level of the agricultural activity is more appropriate.

According to the degree of satisfaction of weather conditions, the score is 2 when satisfied, 0 when not satisfied, and 1 in other cases. According to formula (1), the product of each discriminant condition score value is obtained. If $\mathrm{A}$ is 0 , the meteorological activity meteorological grade is unsuitable. If $A$ is not 0 , the judgment is continued, and each discriminant condition is obtained according to formula (2). For the total value of the score value, if the value of $B$ is $2 n$, the 
meteorological level of the agricultural activity is appropriate, otherwise the weather level of the agricultural activity is more suitable, and the rule conditions are shown in Table 1.

$$
\begin{aligned}
& A=\prod_{i=1}^{n} X_{i} \\
& B=\sum_{i=1}^{n} X_{i}
\end{aligned}
$$

In the formula:

$A$ is the product of the score values for each discriminating condition.

$X_{i}$ is the i-th discrimination condition score value.

$n$ is The total number of different conditions for a farming activity.

$B$ is the total value of each of the discrimination condition score values.

Table 1. Examples of rules for the rules of agricultural

\begin{tabular}{|c|c|c|c|c|}
\hline $\begin{array}{l}\text { Agricultural } \\
\text { activities }\end{array}$ & Project & $\begin{array}{c}\text { Suitable } \\
\text { conditions }\end{array}$ & $\begin{array}{l}\text { Favorable } \\
\text { condition }\end{array}$ & $\begin{array}{c}\text { Unsuitable } \\
\text { condition }\end{array}$ \\
\hline \multirow{5}{*}{ Fertilizing } & $\begin{array}{c}\text { Pre-day } \\
\text { precipitation }\end{array}$ & $\begin{array}{c}\text { No } \\
\text { precipitation } \\
\text { or } \\
\text { paroxysmal } \\
\text { precipitation } \\
\text {, light rain, } \\
\text { moderate } \\
\text { rain, light } \\
\text { snow } \\
\end{array}$ & & \multirow[t]{2}{*}{$\begin{array}{l}\text { Heavy rain, } \\
\text { heavy snow, } \\
\text { frozen snow }\end{array}$} \\
\hline & $\begin{array}{c}\text { Yesterday's } \\
\text { precipitation }\end{array}$ & $\begin{array}{c}\text { No } \\
\text { precipitation } \\
\text { or } \\
\text { paroxysmal } \\
\text { precipitation }\end{array}$ & $\begin{array}{c}\text { Light rain, } \\
\text { moderate } \\
\text { rain, light } \\
\text { snow }\end{array}$ & \\
\hline & $\begin{array}{c}\text { Daytime } \\
\text { precipitation } \\
\text { during the } \\
\text { day }\end{array}$ & $\begin{array}{c}\text { No } \\
\text { precipitation }\end{array}$ & & $\begin{array}{c}\text { Precipitation } \\
\text { (rain, snow) }\end{array}$ \\
\hline & $\begin{array}{c}\text { Average } \\
\text { daily } \\
\text { temperature }\end{array}$ & $<28^{\circ} \mathrm{C}$ & & $\geq 28^{\circ} \mathrm{C}$ \\
\hline & $\begin{array}{c}\text { Daytime } \\
\text { wind speed }\end{array}$ & $\leq$ Level 3 & & $>$ Level 3 \\
\hline \multirow{3}{*}{$\begin{array}{l}\text { Spraying } \\
\text { pesticide }\end{array}$} & $\begin{array}{c}\text { Daytime } \\
\text { precipitation } \\
\text { during the } \\
\text { day }\end{array}$ & $\begin{array}{c}\text { No } \\
\text { precipitation }\end{array}$ & & $\begin{array}{r}\text { Precipitation } \\
\text { (rain, snow) }\end{array}$ \\
\hline & $\begin{array}{c}\text { Average } \\
\text { daily } \\
\text { temperature }\end{array}$ & $<5^{\circ} \mathrm{C}$ & $3 \sim 5^{\circ} \mathrm{C}$ & $\leq 3^{\circ} \mathrm{C}$ \\
\hline & $\begin{array}{c}\text { Daytime } \\
\text { wind speed }\end{array}$ & $\leq$ Level 3 & & $>$ Level 3 \\
\hline \multirow[t]{2}{*}{ Watering } & $\begin{array}{c}\text { Pre-day } \\
\text { precipitation }\end{array}$ & $\begin{array}{c}\text { No } \\
\text { precipitation } \\
\text { or } \\
\text { paroxysmal } \\
\text { precipitation } \\
\text {, light rain, } \\
\text { moderate } \\
\text { rain, light } \\
\text { snow } \\
\end{array}$ & & \multirow[t]{2}{*}{$\begin{array}{l}\text { Heavy rain, } \\
\text { heavy snow, } \\
\text { frozen snow }\end{array}$} \\
\hline & $\begin{array}{c}\text { Yesterday's } \\
\text { precipitation }\end{array}$ & $\begin{array}{c}\text { No } \\
\text { precipitation } \\
\text { or } \\
\text { paroxysmal } \\
\text { precipitation }\end{array}$ & $\begin{array}{c}\text { Light rain, } \\
\text { moderate } \\
\text { rain, light } \\
\text { snow }\end{array}$ & \\
\hline
\end{tabular}
production of agricultural products

\begin{tabular}{|l|c|c|l|l|}
\hline & $\begin{array}{c}\text { Daytime } \\
\text { precipitation } \\
\text { during the } \\
\text { day }\end{array}$ & $\begin{array}{c}\text { No } \\
\text { precipitation } \\
\text { or } \\
\text { paroxysmal } \\
\text { precipitation } \\
\text { light rain }\end{array}$ & & \\
\cline { 2 - 5 } & $\begin{array}{c}\text { Maximum } \\
\text { temperature } \\
\text { of the day }\end{array}$ & $>4^{\circ} \mathrm{C}$ & & \\
\hline
\end{tabular}

3.3.3 Water, fertilizer and pesticide integrated process flow algorithm combined with meteorological information

According to the growth stage of the crop, the water content of the soil, the temperature of the air in the past 3 days, the air temperature and temperature forecast in the last 3 days, and the forecast of precipitation, the integrated process of water, fertilizer and pesticide is adjusted, and the process change response is first, the water, fertilizer and pesticide integrated controller is the length of the output control time. Second, the control of the opening and closing angle of the valve changes the pressure of the water delivery pipe ${ }^{[8]}$. The algorithm stipulates that when the agricultural activities are appropriate, the basic control ratio of water, fertilizer and pesticide integration is $100 \%$, and the basic control ratio is increased or decreased according to multiple impact factors. The algorithm implementation steps are as follows:

Step 1: according to the conditions of Table 1 and the rules, combined with the meteorological data of the previous 3 days and 3 days later, determine whether the agricultural activities are appropriate. If it is not suitable for the controller to feedback to the user, do not carry out this farming activity, and withdraw from the integrated operation process of water, fertilizer and pesticide; if it is suitable to transfer to the second step. The first step solves the problem of controlling the control of water, fertilizer and pesticide by meteorological conditions.

Step 2: after judging the suitable operation of water, fertilizer and pesticide integration, according to the different farming activities such as fertilization, spraying, irrigation, etc., combined with the most critical climatic factors affecting the agricultural activities, dynamically assigning water diversion, topdressing and hydration the relationship between time ${ }^{[9]}$. The weighting value of the meteorological information related to this agricultural activity is assigned, and the weight distribution example table is shown in Table 2. And go to the third step to calculate the time of this farming operation.

Step 3: matching the crop growth stage according to the system time, extracting the influence weight and the hydration time ratio of the meteorological elements required for the growth stage, and transferring to the fourth step.

Step 4: When the water, fertilizer and pesticide integrated system is installed, the controller sets a default water diversion time, top dressing time and replenishment time for the planting object. Due to changes in weather conditions, the influence weights and time ratios of meteorological elements are obtained from Table 2, Table 3, and Table 4, and the time of water diversion and replenishment time is changed, thereby completing the change of the integrated process of water, fertilizer and pesticide. After calculating the time in each step, move to the fifth step.

Step 5: The controller issues control commands to the control port according to the length of each phase and the time-to-front relationship, respectively controlling the opening and closing of the water spray valve, the fertilizer valve, and the spray valve until each stage is set. Time is up and an operation completion message is sent to the user. 
Table 2. Example of the influence weight of meteorological factors on fertilization activities of a planting object

\begin{tabular}{|c|c|c|}
\hline $\begin{array}{c}\text { Agricultural } \\
\text { activities }\end{array}$ & Fertilizing & Figures \\
\hline $\begin{array}{c}\text { Effective } \\
\text { accumulated } \\
\text { temperature }\end{array}$ & Positive weight & 10 \\
\cline { 2 - 3 } & Negative weight & 10 \\
\hline $\begin{array}{c}\text { Sunshine } \\
\text { duration }\end{array}$ & Positive weight & 10 \\
\cline { 2 - 3 } & Negative weight & 10 \\
\hline \multirow{2}{*}{\begin{tabular}{c} 
Soil moisture \\
\cline { 2 - 3 }
\end{tabular}} & Positive weight & 20 \\
\hline $\begin{array}{c}\text { Water diversion } \\
\text { time ratio }\end{array}$ & Negative weight & 20 \\
\hline
\end{tabular}

Table 3. Example of the influence weight of meteorological factors on pesticide spray activities of a planting object

\begin{tabular}{|c|c|c|}
\hline $\begin{array}{c}\text { Agricultural } \\
\text { activities }\end{array}$ & Spraying pesticide & Figures \\
\hline \multirow{2}{*}{$\begin{array}{c}\text { Effective } \\
\text { accumulated } \\
\text { temperature }\end{array}$} & Positive weight & 10 \\
\hline & Negative weight & 10 \\
\hline \multirow{2}{*}{$\begin{array}{l}\text { Sunshine } \\
\text { duration }\end{array}$} & Positive weight & 10 \\
\hline & Negative weight & 10 \\
\hline \multirow{2}{*}{ Soil moisture } & Positive weight & 20 \\
\hline & Negative weight & 20 \\
\hline $\begin{array}{c}\text { Water diversion } \\
\text { time ratio }\end{array}$ & & $1: 1$ \\
\hline
\end{tabular}

Table 4. Example of the influence weight of meteorological factors on water spray activities of a planting object

\begin{tabular}{|c|c|c|}
\hline $\begin{array}{c}\text { Agricultural } \\
\text { activities }\end{array}$ & Spraying water & Figures \\
\hline $\begin{array}{c}\text { Effective } \\
\text { accumulated } \\
\text { temperature }\end{array}$ & Positive weight & 0 \\
\cline { 2 - 3 } & Negative weight & 0 \\
\hline $\begin{array}{c}\text { Sunshine } \\
\text { duration }\end{array}$ & Positive weight & 0 \\
\cline { 2 - 3 } Soil moisture & Positive weight & 0 \\
\cline { 2 - 3 } & Negative weight & 20 \\
\hline $\begin{array}{c}\text { Water diversion } \\
\text { time ratio }\end{array}$ & & $\begin{array}{c}\text { No rehydration } \\
\text { time }\end{array}$ \\
\hline
\end{tabular}

\section{CONTROL PRINCIPLE OF WATER, FERTILIZER AND PESTICIDE INTEGRATED CONTROL DEVICE}

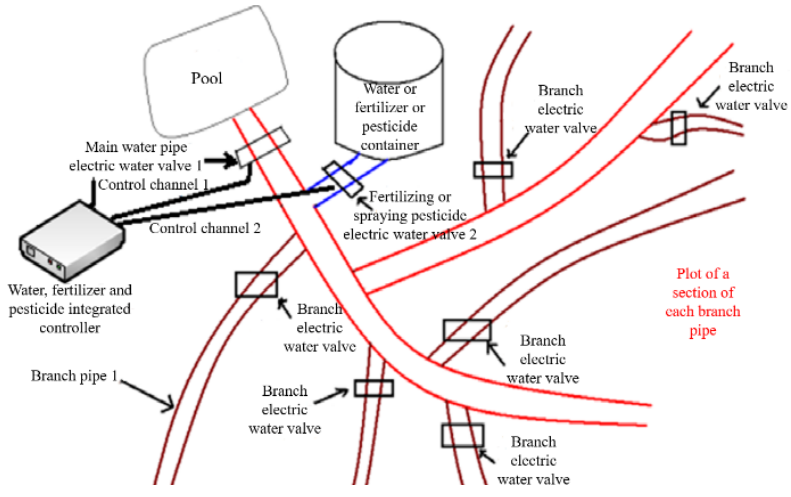

Figure. 1 Schematic diagram of water, fertilizer and pesticide integration

Description:

(1) Each branch is fitted with an electric water and fertilizer, and each electric water valve is equipped with a separate controller. Each controller can communicate independently with the cloud management center. The watering area of each branch pipe determines the area to be watered according to the geographical environment of the mountain area or the actual conditions of water pressure.

(2) The main water pipe electric valve and the fertilization and pesticide spray electric valve are controlled by the same controller, and the controller communicates with the cloud management center independently.

The water, fertilizer and pesticide integration function is completed by the front and rear logic and switch control time of the main water pipe and the fertilization electric valve.

(3) Each controller adopts low-power design and is powered by solar + battery to reduce the construction difficulty on site. The principle of connection between the power supply and the electric water valve is shown in Figure 2.

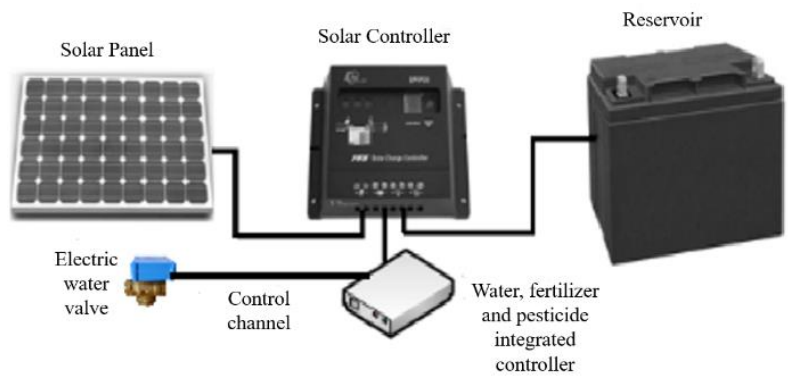

Figure. 2 Water, fertilizer and pesticide integrated controller solar power supply and electric water valve connection schematic

\section{CONCLUSION}

In summary, based on the different dynamics of planting objects, soil properties, weather changes and other actual conditions, the corresponding control methods of water spray, fertilization and pesticide spray can not only achieve "three sections" (water saving, fertilizer saving, pesticide saving), "three provinces" (work-saving, labor-saving, worry-free) and "three increase" (increasing production, increasing income, increasing efficiency), and can fully invoke meteorological big data to participate in all key aspects of crop growth, at the 
largest To the extent that the crops are combined with the actual environment in which they are grown, it is possible to adapt to local conditions, avoid pollution and damage to the soil by chemical substances, and ensure healthy foods that are green and environmentally friendly at the production site. The degree of focus then dynamically influences or changes. The water, fertilizer and pesticide integrated automatic control equipment of this project is an important response to the background of the rapid development of modern agriculture and environmental sustainable development, and is of great significance "Technology No.1".

\section{REFERENCES}

[1] Jing'ai Wang, Peijun Shi, Ping Wang, et al. Temporal and Spatial Patterns of Natural Disasters in China [M]. Beijing: Science Press, 2006.

[2] Dahe Qin. Major meteorological disasters affecting China and its development trend [J]. China Emergency Rescue, 2008, 3(6): 4-6.

[3] Ling Liu, Yizhuo Sha, Yueming Bai. Regional distribution of major agricultural meteorological disasters in China and countermeasures for disaster reduction [J]. Journal of Natural Disasters, 2003, 2(2):
91-97.Tavel, P. 2007 Modeling and Simulation Design. AK Peters Ltd.

[4] Wei Cai et al. Software Development of Agricultural Pest Expert System Based on VB.NET[J]. Agriculture Network Information, 2005(12): 28-29, 33.

[5] Ying Han, Xi Pu. China's meteorological services and their benefit evaluation [J]. Meteorological Science, 2010, (3).

[6] Chunyi Wang, Shili Wang. Research progress on monitoring, early warning and assessment techniques for major agricultural meteorological disasters in China in the past 10 years[J]. Acta Meteorologica Sinica, 2005, (5).

[7] Jinlong Fan et al. Crop yield prediction system based on agro-meteorological model[J].Chinese Journal of Agrometeorology,2003(2):46-48,51.

[8] Cheng Li, Xiaoyue Xiao. Application of Meteorological Information Service in Agricultural Production[J]. Village Science and Technology, 2017(10): 66-67.

[9] Yuan Qiu. Preliminary Study on Risk Analysis of Agricultural Meteorological Disasters[J]. Agriculture and Technology, 2013(7): 195-195. 